\title{
A Filologia editorial na era digital
}

Tainá Matos Lima Alves Boaventura ${ }^{2}$

Taylane Vieira dos Santos ${ }^{3}$

Patrício Nunes Barreiros ${ }^{4}$

\section{Introdução}

OS ACERVOS DE ESCRITORES SÃO LUGARES DE MEMÓRIA, ESPAÇOS VISTOS COMO IMPORTANTES FONTES RESPONSÁVEIS POR guardar e transmitir a história de um povo, de uma memória coletiva. Diante das práticas editoriais que estão sendo realizadas na contemporaneidade, o acervo é um ambiente que permite também que textos e paratextos dialoguem e possam ser estudados em suas relações. Cada obra carrega consigo uma infinidade de contextos relacionados a ela. Acreditamos que editar um texto que faz parte de um arquivo e apresentá-lo, sem explorar suas relações com o conjunto documental ao qual ele pertence, seria privar os leitores dos contextos de produção, circulação, recepção e apropriação, que ajudam muito na compreensão ampla desse texto. As edições impressas tradicionais não têm conseguido dar conta das infinitas relações existentes entre o texto e o conjunto do seu acervo. Diante disto, as tecnologias digitais em diálogo com os estudos filológicos, na contemporaneidade, vêm contemplando tais singularidades bem como a complexidade textual, através das edições digitais ou hiperedições.

O acervo de Eulálio Motta, por exemplo, é o reflexo de sua imagem: esboça as identidades do escritor, e preserva tanto a sua memória individual quanto a coletiva no que se refere ao quadro sócio-histórico do século XX, em Mundo Novo, cidade do interior da Bahia. O acervo é constituído de documentos acumulados pelo próprio escritor entre os anos de 1923 e 1988 ; é composto por materiais de diferentes naturezas, incluindo rascunhos e esboços de obras inacabadas, manuscritos e datiloscritos de textos éditos e inéditos, diários, cadernos de anotações diversas, correspondências, fotografias, documentos de identificação, diplomas, esboços de projetos editoriais, coleções de jornais e panfletos, instrumentos de trabalho como a sua máquina de escrever.

Esse acervo configura-se como um espaço que desestabiliza a unidade, obrigando o editor a fugir de concepções engessadas em busca do ânimo autoral. Editar textos que integram um conjunto documental de natureza diversa, como é o caso do acervo de Eulálio Motta, reclama do filólogo, uma abordagem transdisciplinar, que versa sobre uma aproximação entre campos disciplinares diversos, atualizando e revendo sua prática editorial, e também, um redimensionamento para a noção de obra e de texto, tendo em vista que os documentos arquivados estão interligados por uma rede de sentidos.

Os textos eulalianos são múltiplos, apresentam um caráter móvel, nômade e se relacionam com outros documentos, sendo necessária a valorização da multiplicidade em detrimento da unidade e o rompimento com propostas hierarquizantes. Os textos de arquivos reclamam do filólogo reflexões acerca da representação complexa dos mesmos a partir de um modelo que foge do padrão linear e temporal, dando lugar a uma concepção complexa e rizomática. Isto posto, buscamos, através da exploração por meio das interfaces entre a Filologia, Crítica Textual, Crítica Genética, História Cultural, Sociologia dos

\footnotetext{
${ }^{1}$ O presente trabalho foi realizado com apoio da Fundação de Amparo à Pesquisa do Estado da Bahia - Brasil (Fapesb).

${ }^{2}$ Doutoranda em Estudos Linguísticos pelo Programa de Pós-Graduação em Estudos Linguísticos (PPGEL) da Universidade Estadual de Feira de Santana. E-mail: taialves_08@hotmail.com

${ }^{3}$ Doutoranda em Estudos Linguísticos pelo Programa de Pós-Graduação em Estudos Linguísticos (PPGEL) da Universidade Estadual de Feira de Santana. E-mail: tayvieira2549@gmail.com

${ }^{4}$ Professor na Universidade Estadual de Feira de Santana. Bolsista de produtividade - CNPq/Fapesb. E-mail: patriciobarreiros@hotmail.com
} 
Textos, atreladas ao ambiente digital, promover uma discussão acerca de uma edição que contextualize a obra do autor ao passo que elucide seus códigos linguísticos, bibliográficos e contextuais. A forma do texto, a dimensão material e todo o conjunto de propriedades físicas, visuais, etc., afetam e participam da construção de seu sentido, do seu significado.

O modelo de hiperedição, empregado para editar os documentos do arquivo de Eulálio Motta, democratiza o acesso a informações de reuniões de documentos importantes que são omitidos nas versões impressas e promove, por meio do hipertexto, a representação complexa dos mesmos a partir de um olhar rizomático que promove novas formas de leitura, recepção e circulação social dos textos.

\section{As Humanidades Digitais e as Práticas Editoriais}

É evidente que o processo de comunicação científica vem sendo impactado pelo uso das novas tecnologias. Esse impacto é perceptível em todas as áreas do conhecimento, inclusive na área de Humanidades. De acordo com Costa, "esse uso crescente da comunicação eletrônica tem provocado mudanças no processo de comunicação científica propriamente dita, na medida em que suscita alterações dentro das comunidades científicas"

As Humanidades Digitais surgem da aproximação das Ciências Humanas com as tecnologias digitais. No âmbito dos estudos filológicos e da Crítica Textual, o diálogo com as Ciências da Computação implicou em mudanças de concepções teóricas e metodológicas, fornecendo aos pesquisadores caminhos inovadores por meio de programas computacionais. Lose ${ }^{6}$ afirma que desde o despontar definitivo das "tecnologias digitais para edição, editoração, digitalização de textos no universo acadêmico da área das Letras, em especial, no que tange à filologia moderna, inúmeras discussões e desconfortos tem tido espaço em eventos da área”.

De acordo com Paixão de Souza ${ }^{7}$, o crescimento do volume de objetos textuais digitalizados nas últimas décadas foi responsável por um verdadeiro dilúvio de informações que acarretou sensações de êxtase e pânico nos pesquisadores. Para a autora, tal impacto nas disciplinas humanísticas em geral tem sido bastante discutido por muitos autores no campo das chamadas "Humanidades Digitais".

Percebe-se que o surgimento da era digital forçou a sociedade a ressignificar o seu olhar e as suas formas de lidar com o mundo e, consequentemente, com o texto em suas diferentes modalidades. A difusão digital sobre as edições filológicas configura-se em uma nova forma de pensar o trabalho de edição. Trata-se de uma mudança de paradigmas, de uma transformação hermenêutica do fazer filológico. As edições eletrônicas têm permitido tornar visível, por exemplo, a pluralidade de textos e a instabilidade histórica dos mesmos, que a versão impressa não dava conta de mostrar.

Lose $^{8}$ sustenta que a edição digital "mostra-se um tipo completamente adequado à Filologia que precisa não somente trabalhar o texto, mas também o paratexto, as informações que contextualizam e dão sentido ao documento editado.” Ainda, de acordo com a pesquisadora "O entorno do texto é sempre fundamental para uma boa edição e a edição digital possibilita esse diálogo de forma natural e soberana." ${ }^{9}$

Dessa forma, a não-linearidade, a dinamicidade e a multiplicidade que o ambiente digital promove, modificou o pensamento humano e suas práticas, tornando-se um dos fundamentos da atividade humana contemporânea. Nesse sentido, para Lucía Megías:

\footnotetext{
${ }^{5}$ Costa, 2000, p. 97.

${ }^{6}$ 2011, p. 14.

${ }^{7} 2020$.

${ }^{8}$ 2011, p. 16.

${ }^{9}$ LOSE, 2011, p. 16.
} 
A informática se estabeleceu como uma nova tecnologia que deslocou todas as existentes. [...] A extensão do meio digital como forma de difusão do conhecimento e da informação é uma verdadeira revolução, que vai além da mudança do suporte de escrita (do papiro ao pergaminho, e deste ao papel), pois afeta a própria materialidade do próprio texto (um de seus princípios frente à oralidade), às técnicas de reprodução e difusão e, portanto, as formas de recepção e de leitura. [...] Cabe a nós, filólogos, levantar o debate sobre como deverão se configurar, suas possibilidades e características. $^{10}$

No bojo dessas evoluções teóricas surgem também novas formas de edição com o apoio do meio digital. O trabalho manual vem sendo historicamente desenvolvido de forma concatenada ao uso de tecnologias computacionais. O trabalho filológico em suporte digital surge com a própria invenção do computador, entretanto, de acordo com Paixão de Sousa ${ }^{11}$, foi na virada entre o século XX e o XXI "que veremos multiplicarem-se iniciativas de construção de repositórios e ferramentas para a edição filológica, e surgir um grande número de periódicos dedicados ao tema das edições eletrônicas". Ainda de acordo com a autora:

No universo dos estudos fundados no texto em geral, e no mundo dos estudos do texto escrito em épocas passadas em particular, esse dilúvio de objetos tem causado euforia entre os pesquisadores, subitamente brindados pela produção em cascata de fontes para seus estudos historiográficos em geral. ${ }^{12}$

As ferramentas computacionais têm permitido possibilidades amplas e abertas para a edição filológica digital em contraposição à mecânica. O diálogo interdisciplinar, que os estudos filológicos vêm construindo ao longo dos anos com o meio digital tem se efetivado de forma real e não apenas acessória, contribuindo para o surgimento de novas materialidades do texto em suporte digital. As técnicas de edição filológica pautam-se na ideia de que "a edição eletrônica amplia os horizontes técnicos do trabalho filológico, por libertar as técnicas de representação editoriais das limitações materiais colocadas anteriormente pela tecnologia do impresso"13

Dessa forma, as ferramentas e programas computacionais têm auxiliado o trabalho investigativo, mediando os processos de interpretação dos textos junto ao público leitor. Sobre isto Emiliano destaca:

As tecnologias da informação põem hoje à disposição dos filólogos variadíssimos recursos (aplicações, utilitários, redes, suportes para armazenamento de grandes quantidades de texto) para editar, processar e analisar textos. [...] Estes desenvolvimentos e avanços interpelam decisivamente os filólogos portugueses, que são obrigados a repensar os procedimentos e estratégias editoriais praticados até o advento e generalização do computador pessoal: não é possível continuar a pensar as edições como objectos fechados e fixados imutavelmente na página impressa em papel, ou como simples transposições dos textos [...] para o suporte impresso. [...]. ${ }^{14}$

Percebe-se, então, que a Filologia, ao longo do tempo, tem adotado diferentes métodos para a edição de textos. Sua aproximação com outras áreas do conhecimento, como as Ciências da Computação tem permitido inseri-la nas chamadas

\footnotetext{
${ }^{10}$ LUCíA MEgías, 2010, p. 229, tradução nossa.

11 2013, p. 113.

12 PaIXÃo de SoUsa, a publicar.

${ }^{13}$ PaIXÃo de SoUSA, 2013, p. 127.

${ }^{14}$ EMILIANO, 2005, p. 141.
} 
“Humanidades Digitais”, garantindo um diálogo transdisciplinar que possibilita o filólogo a valorizar os códigos linguísticos, extralinguísticos, bibliográficos e contextuais dos textos manipulados, através das ferramentas computacionais.

\section{A práxis filológica em meio digital}

As humanidades digitais, como já foi frisado, têm proporcionado um diálogo frutífero com os estudos filológicos. As práticas editoriais estão indo além do estabelecimento do texto e da fixação engessada em busca do ânimo autoral. Os filólogos, na contemporaneidade, direcionam suas edições para a produção de arquivos hipertextuais, disponibilizados em rede ou em suportes da informática. Para cumprir o seu propósito, os pesquisadores filólogos transitam por diferentes caminhos e tomam de outros campos teórico-metodológicos recursos para a prática filológica, estabelecendo vínculos entre saberes, conforme o objeto de estudo e o objetivo de pesquisa. Uma edição digital, por sua inerente mobilidade, reproduz o texto em sua própria movência e complexidade. Tais práticas buscam compartilhar as relações entre os paratextos, prototextos e todos os documentos relacionados ao objeto de estudo, evidenciando características que dão a conhecer aspectos da produção, transmissão e recepção dos textos.

Diante dessas mudanças epistemológicas e metodológicas, o acervo de escritor é redimensionado, deixa de ser visto somente como fonte de estudo e passa a ser concebido como um objeto histórico, um construto simbólico. Os acervos de escritores são considerados como lugares de memória, por salvaguardar os registros históricos, políticos, literários e sociais de escritores. O estudo do/no acervo permite ao pesquisador "conhecer" o acontecido, ter contato com os bastidores de produção do escritor, contribuindo dessa maneira para a preservação da memória e para o alargamento da noção de obra. É um espaço aberto, amplo que permite que o objeto de estudo dialogue com a infinidade de prototextos e paratextos e possam ser estudados em suas infinitas relações. Como diz Rettenmaier ${ }^{15}$, “A literatura não é feita apenas de obras literárias, pois há um mundo no entorno de cada livro. Da mesma forma, um livro não é feito apenas de seu texto. Há uma plêiade de textos ao seu redor, ao lado e abaixo dele".

No caso dos textos publicados, o estudo dos prototextos, por exemplo, rascunhos com emendas, substituições, supressões etc., e dos paratextos, com documentos que apresentam informações sobre a elaboração de um dado texto, como as correspondências e anotações, ou que auxiliam na compreensão do seu conteúdo (escritos que compartilham a mesma temática), fornecem ao pesquisador o conhecimento das etapas de criação a partir da análise dos procedimentos escriturísticos utilizados pelo escritor, das escolhas autorais, motivadas pelas sugestões de terceiros e das ideias anotadas. A obra deixa de ser a coletânea de textos literários acabados e passa a ser constituída também por toda a produção, escrita ou não, em que se possa reconhecer uma relevância para a literatura, seja por um viés biográfico, cultural ou autoral. ${ }^{16}$

Com base nos estudos propostos por Genette ${ }^{17}$, depreende-se que os paratextos são divididos em dois grandes subconjuntos, o peritexto e o epitexto. O peritexto se refere aos paratextos previamente elaborados para o texto maior, como rascunhos, esboços, projetos diversos; e o epitexto está relacionado com os materiais que circulam fora da obra, como entrevistas, correspondências, notícias em jornais, revistas, cartas e etc. No acervo de Eulálio Motta, nos deparamos tanto

\footnotetext{
15 2008, p. 144.

${ }^{16}$ SANTIAGO, I., S.; BARREIROS, L., P., 2019, p. 104.

17 2006, p. 9-10.
} 
com os peritextos quanto com os epitextos, elementos imprescindíveis para a elucidação, interpretação e análise crítica de suas obras. Segundo Lucía Megías, os documentos paratextuais,

[...] não encontram seu lugar nas edições críticas tradicionais: Fac-símiles, transcrições (semi) paleográficas dos testemunhos base para os estudos linguísticos; apresentações críticas dos mesmos (de maneira optativa); intertextos: fontes textuais da obra; intratextos: fragmentos de outros textos do autor / época em que aparece o mesmo texto editado; e numeroso material de apoio - tanto iconográfico como sonoro ou textual - que se considera pertinente e necessário para a compreensão global do texto. ${ }^{18}$

Todos os documentos relacionados à obra editada precisam ser explorados em toda sua complexidade, pois são esses materiais que elucidam e atribuem sentido ao objeto de estudo do sujeito-editor.

No acervo de Eulálio Motta, foram identificados cadernos contendo textos manuscritos correspondentes a projetos de livros inéditos, com textos passados a limpo e com indicação de que deveriam ser enviados aos editores. Inicialmente, foram identificados oito projetos editoriais ${ }^{19}$, posteriormente, três novos projetos de livros foram acrescentados à lista: (i) uma coletânea dos textos jornalísticos $^{20}$; (ii) coletânea de textos que tratam da emancipação de Piritiba, intitulado Bofetada; e Por uma ação católica, que Eulálio pretendia reunir as crônicas religiosas que constam no caderno Farmácia São Jose ${ }^{21}$.

Dentre os projetos editoriais, destaca-se o caderno Canções de meu caminho que a partir de sua estrutura orgânica, é considerado projeto de obra com textos passados a limpo, servindo somente para este propósito; e o projeto editorial Flôres e espinhos mencionado pelo autor nos cadernos, contendo índices dos textos que fariam parte da publicação, conforme mostrado abaixo:

\footnotetext{
${ }^{18}$ Megías (2010, p. 244)

${ }^{19}$ BARREIROS, 2009.

${ }^{20}$ Barreiros; Santiago, I., 2016.

${ }^{21}$ Barreiros; SANTIAGO, S., 2016.
} 


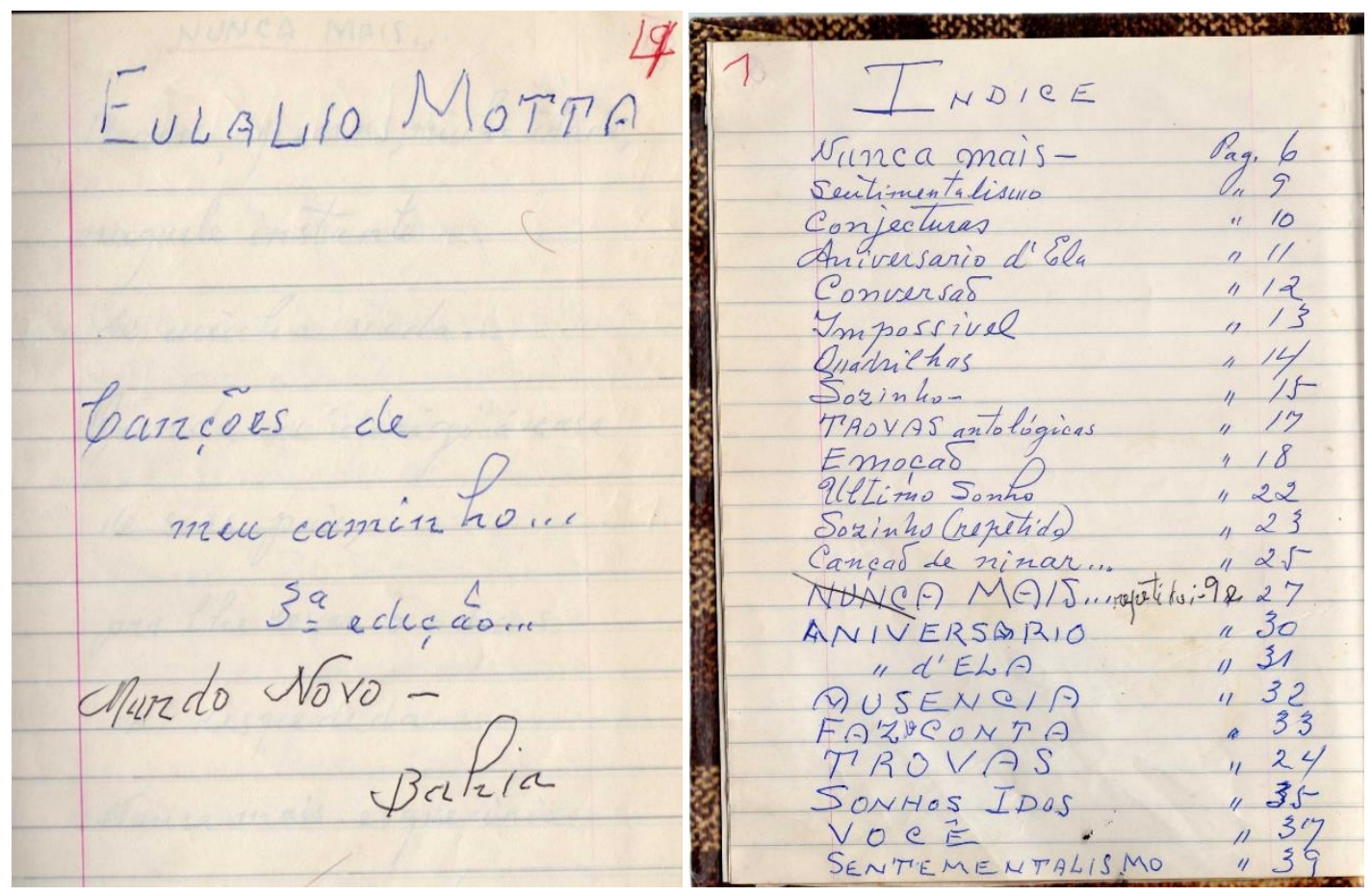

Fig. 1: Fac-símiles das f.6r e f.4v do caderno Canções de meu caminho $3^{\mathrm{a}}$ edição.

Fonte: Acervo do escritor

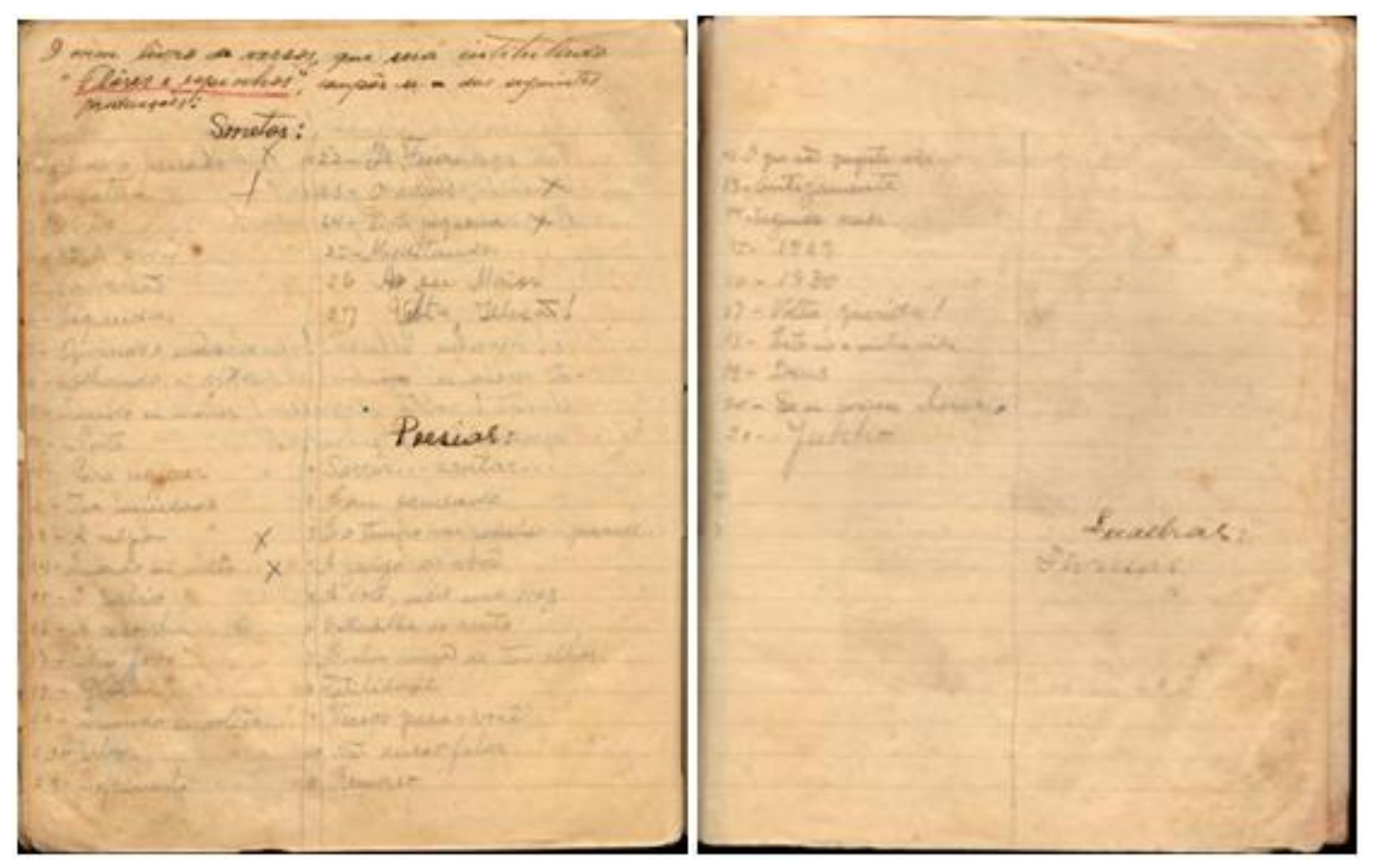

Fig. 2: Fac-símiles das f.111v e f.112r do Caderno Lágrimas.

Fonte: Acervo do escritor. 
Ambos os projetos dialogam com uma gama de documentos presentes no acervo de Eulálio Motta, a exemplo de cartas, citações em jornais sobre as edições, fotografias, anotações avulsas, materiais que elucidam o processo criativo do escritor e atribuem sentido à gênese da obra. Tais materiais, aparentemente dispersos são reunidos pelo editor a partir de critérios prédefinidos com a finalidade de construir um dossiê arquivístico. Para Barreiros ${ }^{22}$ a grande vantagem das edições digitais é que todos esses documentos do dossiê arquivístico podem ser vinculados ao texto a partir de links eletrônicos ou visualizados em menus específicos, organizados pelo editor.

Ao construir o dossiê arquivístico, o filólogo precisa fugir de concepções hierarquizantes e lineares e buscar a representação multifacetada, complexa e móvel dos textos a partir de um modelo rizomático sobre o acervo. O modelo de rizoma defendido por Deleuze e Guattari ${ }^{23}$ valoriza as multiplicidades em detrimento da unidade, rompe com as propostas hierarquizantes buscando a representação da complexidade dos objetos. Na visão dos autores:

Um rizoma não começa nem conclui, ele se encontra sempre no meio, entre as coisas, inter-ser, intermezzo. A árvore é filiação, mas o rizoma é aliança, unicamente aliança. A árvore impõe o verbo "ser", mas o rizoma tem como tecido a conjunção "e... e... e...". Há nesta conjunção força suficiente para sacudir e desenraizar o verbo ser. Entre as coisas não designa uma correlação localizável que vai de uma para outra e reciprocamente, mas uma direção perpendicular, um movimento transversal que as carrega uma e outra, riacho sem início nem fim, que rói suas duas margens e adquire velocidade no meio. ${ }^{24}$

Tanto a obra Canções de meu caminho quanto o projeto Flores e espinhos permitem que sejam analisados seguindo essa perspectiva rizomática, pois ambas as produções se conectam com uma grande quantidade de materiais dentro e fora do acervo de Eulálio Motta. E essas conexões perpassam por temas diversos relacionados às memórias, ao posicionamento político e religioso do próprio escritor e à cultura. Vinculada à conexão, a heterogeneidade consiste na supressão da barreira tipológica, grande contribuinte das construções hierarquizantes. Desse modo, o rascunho, a anotação, as leituras prévias, as produções autorais e não autorais, a estaticidade do impresso e os recursos hipermidiáticos, todos se conectam em pé de igualdade, passando a integrar a realidade textual, reinventando- $\mathrm{a}^{25}$. Debruçar-se no acervo sob essa perspectiva de rizoma é ampliar o olhar sobre os documentos, é romper com a visão de que um sobrepõe o outro, é mapear o diálogo entre os textos a partir de suas complexidades. Desse modo, as “[...] cadeias semióticas de toda natureza são aí conectadas a modos de codificação muito diversos, cadeias biológicas, políticas, econômicas, etc." ${ }^{26}$

Diante das mudanças paradigmáticas ocorridas por meio da Nova Crítica, da Teoria Literária e da Informática, no âmbito da Crítica Textual, as edições digitais vêm adquirindo cada vez mais espaço na práxis filológica contemporânea. Em ambiente digital, as noções de texto e materialidade, são reconfiguradas, ampliadas; assim como a relação entre autor, editor e leitor. Para Chartier $^{27}$, a textualidade eletrônica redefine a materialidade do texto, altera as formas de construção dos discursos e as práticas de leitura e de construção do sentido”. Segundo o autor,

\footnotetext{
22 2015, p. 184-185.

${ }^{23} 1995$.

${ }^{24}$ Deleuze; Guattari, 1995, p. 37.

${ }^{25}$ SANTIAGO, S.; I.; BarReiros, P.; L., 2019, p. 114.

${ }^{26}$ Deleuze; Guattari, 1995, p. 15.

272002.
} 
O texto eletrônico, tal qual o conhecemos, é um texto móvel, maleável, aberto. O leitor pode intervir em seu próprio conteúdo e não somente nos espaços deixados em branco pela composição tipográfica. Pode deslocar, recortar, estender, recompor as unidades textuais das quais se apodera. $^{28}$

Essa leitura aberta, que rompe com a linearidade impõe o leitor a colocar em prática sua autonomia para consultar documentos (imagens, músicas, cartas, jornais, e etc.) e traçar sua leitura em meio ao labirinto textual disponível na tela do computador. O texto digital precisa ser visto e explorado "como um artefato cultural e social, linguístico e bibliográfico que considere os elementos autor, escriba, manuscrito, tipógrafo, editor, leitor" ${ }^{29}$.

Percebe-se, ao lidar com os documentos de Eulálio Motta, que o autor desenvolveu uma funcionalidade prática para o seu acervo, consultando documentos para escrita e reescrita de textos. Dessa forma, a análise criteriosa dessa documentação é necessária, já que o acervo mantém uma rede de conexões com os textos literários. A edição digital, pelos moldes como vem sendo desenvolvida pela equipe do NeiHD, portanto, promove contextualização, dinamismo, aponta novos caminhos e abre novas possibilidades de leitura e compreensão das obras, valorizando os elementos verbais e não verbais do corpus.

\section{Considerações Finais}

A discussão proposta ilustrou a práxis filológica que vem sendo desenvolvida no contexto da Filologia contemporânea, cujo propósito foi evidenciar que o objeto central das práticas editoriais é o próprio texto e é ele que direciona o tipo de edição a ser realizada pelo sujeito editor.

O vínculo entre a Filologia e as Humanidades digitais têm possibilitado reflexões, ressignificações na concepção de texto, na forma de transmissão e recepção do mesmo; tem proporcionado também novos modelos editoriais que priorizam todas as versões de um texto, que contemplam toda a sua complexidade e diversidade, valorizando sua pluralidade e suas conexões com os paratextos presentes no acervo do escritor, e que não aparecem nas grandes edições tornadas públicas pelas limitações do impresso.

Propomos, por isso, refletir sobre teorias contemporâneas de edição pelas interfaces das Críticas: Textual, Genética e Sociológica, em ambiente digital, apontando novos caminhos do fazer filológico, na contemporaneidade, que vem sendo possibilitada pelos novos suportes eletrônicos.

\section{Referências bibliográficas}

BArreiros, Patrício Nunes. A oficina do escritor e os projetos editoriais de Eulálio de Miranda Motta. Cadernos do CNLF (CiFEFil), v. 13, 2009.

BARREIROS, Patrício Nunes. OPasquineiroda Roça: ahiperedição dos panfletos de Eulálio Motta.Feira deSantana: UEFSEditora, 2015.

BARreiros, Patrício Nunes. SANTIAgo, Iago Gusmão. Eulálio Motta: jornalista de Mundo Novo. Anais. VIII Seminário de Estudos Filológicos Filologia e Humanidades Digitais, Universidade Estadual de Feria de Santana, p. 182-195, 2016.

\footnotetext{
${ }^{28}$ ChARTIER, 2002, p. 25.

${ }^{29}$ LOURENÇO, 2009, p. 244.
} 
revista de crítica genética

Barreiros, Patrício Nunes; SAntiago, Stephanne da Cruz. Edição e estudo do caderno Farmácia São José, de Eulálio Motta. Anais. VIII Seminário de Estudos Filológicos: Filologia e Humanidades Digitais, Universidade Estadual de Feria de Santana, p. 92-105, 2016.

Chartier, Roger. Os desafios da escrita. Tradução de Fúlvia M. L. Moretto. São Paulo: Editora UNESP, 2002.

Costa, Sely M. S. de. Mudanças no processo de comunicação científica: o impacto do uso de novas tecnologias. In: MUELLER, Suzana P. M.; PASSOS, Edilenice (Org.). Comunicação científica. Brasília: UnB, 2000. p. 85-106. (Estudos avançados em Ciência da Informação, 1).

Deleuze, Gilles; Guattari, Felix. Mil platôs - Capitalismo e Esquizofrenia v. 1. Tradução de Aurélio Guerra Neto e Celia Pinto Costa. Rio de Janeiro: Editora 34, 1995.

EMILIANO, António. Tipo Medieval para Computador: uma ferramenta informática para linguistas, historiadores da língua e paleógrafo. Signo. Revista de Historia de la Cultura Escrita (Universidade de Alcalá de Henares), n. 15, (2005), p. 139-176.

Genette, Gerard. Palimpsestos: a literatura de segunda mão. Extratos traduzidos por Luciene Guimarães e Maria Antonia Ramos Coutinho. Belo Horizonte: Edufmg, 2006. Apud FAGUNDES, Carla Ceci Rocha; SANTOS, Rosa Borges dos. Texto e Paratexto: por uma proposta editorial. Anais do XVI CNLF. Rio de Janeiro: CiFEFiL, 2012.

LOSE, Alícia Duhá et al. 2011. Edições digitais de manuscritos: do século XVI ao século XXI. In: CIRILLO, José; PASSOS, MarieHélène Paret (Org.). Materialidade e virtualidade no processo criativo. Vinhedo, SP: Horizonte, 2011, p. 77-99.

LOUREnÇO, Isabel Maria Graça. The William Blake Archive: da gravura iluminada à edição electrônica. 2009. 490f. Tese (Doutorado em Letras) - Instituto de Letras, Universidade de Coimbra, Coimbra, 2009.

LuCía Megías, José Manuel. Reflexiones en torno a las plataformas de edición digital: el ejemplo de la Celestina. In: PoALINI, Devid. (Coord.). De ninguna cosa es alegre posesión sin compañía, estudios celestinescos e medievales en honor del profesor Joseph Thomas Snow. Tomo I. New Work: Seminário Hispánico de Estudios Medievales, p. 226-251, 2010.

PAIXÃo DE SOUSA, Maria Clara. Humanidades Digitais e Linguística Histórica: novos desafios para uma velha disciplina (a sair).

PAIXÃo DE SOUSA, Maria Clara. A Filologia Digital em Língua Portuguesa: Alguns caminhos. In: BAnZA, Ana Paula; GonÇAlves, Maria Filomena (coord.). Património textual e humanidades digitais: da antiga à nova Filologia. Évora: Centro Interdisciplinar de História, Culturas e Sociedades da Universidade de Évora (CIDEHUS); Fundação para a Ciência e a Tecnologia (FCT), p. 113-138, 2013.

Rettenmaier, Miguel. Pesquisa literária e acervo: a maldição dos manuscritos. Revista do Programa de Pós-Graduação em Letras da Universidade de Passo Fundo, v. 4, n. 2, p. 137-145, jul./dez., 2008.

SANTIAGO, Iago Gusmão; SANTIAGo, Stephanne da Cruz; BARreiros, Liliane Lemos Santana; BARreiros, Patrício Nunes. O acervo do escritor e sua conectividade rizomática. Légua \& Meia, Brasil, n. 9, v. 1, p. 101-122, 2019.

Recebido em: 23/07/2021 Aceito em: 30/09/2021 